Article

\title{
Hypovitaminosis D: A Disease Marker in Hospitalized Very Old Persons at Risk of Malnutrition
}

\author{
Virginia Boccardi * (D), Maria Lapenna, Lorenzo Gaggi, Francesco Maria Garaffa, \\ Michele Francesco Croce, Marta Baroni, Sara Ercolani, Patrizia Mecocci $\mathbb{D}$ and \\ Carmelinda Ruggiero
}

Institute of Gerontology and Geriatrics, Santa Maria della Misericordia Hospital, Department of Medicine, University of Perugia, 06123 Perugia PG, Italy; marialapenna89@gmail.com (M.L.); lorenzo.gaggi.ger@gmail.com (L.G.); francescomaria.garaffa@studenti.unipg.it (F.M.G.); michelecroce@hotmail.it (M.F.C.); martabaroni@libero.it (M.B.); saraercolanisara@gmail.com (S.E.); patrizia.mecocci@unipg.it (P.M.); carmelinda.ruggiero@unipg.it (C.R.)

* Correspondence: virginia.boccardi@unipg.it; Tel.: +39-075-578-3524

Received: 5 December 2018; Accepted: 7 January 2019; Published: 9 January 2019

check for updates

\begin{abstract}
Background: Hypovitaminosis D is a frequent condition in elderly subjects. Vitamin D adequacy is best determined by measurement of the 25-hydroxyvitamin $\mathrm{D}-25(\mathrm{OH}) \mathrm{D}$-concentration in the serum. An inverse association exists between $25(\mathrm{OH}) \mathrm{D}$ and cardiovascular, infectious, glucose metabolism, cognitive disorders, and all-cause mortality. Whether $25(\mathrm{OH}) \mathrm{D}$ is a marker of organ diseases is still under debate. We aimed to investigate whether comorbidities were associated with serum $25(\mathrm{OH}) \mathrm{D}$ levels in geriatric inpatients. Methods: This is a retrospective study, including 237 subjects consecutively admitted to an acute care geriatric unit, with available data of $25(\mathrm{OH}) \mathrm{D}$ serum concentrations. $25(\mathrm{OH}) \mathrm{D}$ serum levels were defined according to the following cutoffs: $50-30 \mathrm{ng} / \mathrm{mL}$ (125-75 nmol/L): optimal range; 30-20 ng/mL (75-50 nmol/L): insufficiency; 20-10 ng/mL (5-25 nmol/L): deficiency; and <10 ng/mL (<25 nmol/L): severe deficiency. Comorbidity was assessed using the Cumulative Illness Rating Scale-Geriatric (CIRS-G). Two summary measures were obtained, the Illness Severity Index (CIRS-SI) and the Comorbidity Index (CIRS-CI). Results: 177 (74.68\%) women and 60 (25.32\%) men with mean age of $85 \pm 6$ years old were enrolled. The majority of subjects $(68.6 \%)$ were at risk of malnutrition. Overall, the burden of comorbidity was $1.87 \pm 1.33$ for CIRS-CI and $1.18 \pm 0.40$ for CIRS-SI. 25(OH)D serum concentrations were $10.58 \pm 7.68 \mathrm{ng} / \mathrm{mL}$, with $98.7 \%$ of subjects having vitamin D below $30 \mathrm{ng} / \mathrm{mL}$ and $56.6 \%$ with severe deficiency. An inverse correlation was found between $25(\mathrm{OH}) \mathrm{D}$ and both CIRS-SI $(r:-0.312$; $p<0.0001)$ and CIRS-CI $(r:-0.306 ; p<0.0001)$. Independent of multiple covariates an inverse association between both CIRS-SI $(p<0.0001)$ and CIRS-CI $(p<0.0001)$ and 25(OH)D was confirmed. Both CIRS-SI $(r=0.251, p<0.0001)$ and CIRS-CI $(r=0.137, p=0.016)$ were positively correlated with the length of hospital stay. An inverse correlation was confirmed between serum $25(\mathrm{OH}) \mathrm{D}$ concentrations and CRP $(r=-0.142 ; p=0.041)$. CRP, in turn, positively correlated with CIRS-SI $(r=0.209, p=0.003)$ and CIRS-CI $(r=0.158, p=0.023)$. Both CIRS-SI $(r=0.251, p<0.0001)$ and CIRS-CI $(r=0.137, p=0.016)$ were positively correlated with the length of hospital stay. Conclusions: In hospitalized very old subjects, a higher comorbidity burden is associated with lower $25(\mathrm{OH}) \mathrm{D}$ serum levels. Hypovitaminosis D was correlated with higher inflammatory status, which, together with the comorbidities burden, negatively influenced the length of hospital stay.
\end{abstract}

Keywords: biomarkers; geriatric assessment; hospital-related; multimorbidities; malnutrition; vitamin D 


\section{Introduction}

Vitamin D and parathyroid hormone (PTH) are two major regulators of mineral metabolism. They play critical roles in the maintenance of calcium and phosphate homeostasis as well as the development and maintenance of bone health. Hypovitaminosis D is a highly prevalent condition among older adults, ranging in occurrence from $50 \%$ to $90 \%$, depending on the definition used and the setting $[1,2]$. Vitamin D deficiency most commonly results from inadequate sunlight exposure but can also be caused by inadequate nutritional intake or disorders limiting its metabolism [2].

Vitamin $\mathrm{D}$ status is best determined by measurement of the 25-hydroxyvitamin $\mathrm{D}-25(\mathrm{OH}) \mathrm{D}$-concentration in the serum. Several observational studies found that the concentration of $25(\mathrm{OH}) \mathrm{D}$ is inversely associated with all-cause mortality in the general population [3], as well as with the development and progression of several conditions, including cancer, cardiovascular diseases, glucose metabolism disorders, neurodegenerative diseases, infections, and autoimmune conditions [4-6].

In hospitalized adults, the greater the severity of chronic diseases the lower the $25(\mathrm{OH}) \mathrm{D}$ serum concentration, irrespective of the number of diseases [7], with a higher risk of clinical instability [8] and mortality $[9,10]$. Also, critical hospitalized patients with hypovitaminosis D experience an increased risk of complications from hospital-acquired infections [11] and a longer length of hospital stay, suggesting that hypovitaminosis D may be a marker of severity of comorbidity and length of hospital stay [12-14].

However, systematic reviews and metanalysis investigating the effects of vitamin D supplementation on disease occurrence and progression failed to show encouraging findings, leading to the hypothesis that serum $25(\mathrm{OH}) \mathrm{D}$ concentrations would essentially be a marker of illness status [15]. Ultimately, a randomized, double-blind trial revealed that the administration of high-dose vitamin D3 compared with placebo reduced hospital mortality among critically ill adult patients with severe vitamin D deficiency, without reducing the length of hospital stay [16]. Thus, other factors may have a more significant role in determining the length of hospital stay. The oldest critically ill patients usually have severe vitamin D deficiency [17] and suffer a higher burden of comorbidity, and therefore may benefit more from interventions. Thus, we aimed to investigate: (1) the association between serum $25(\mathrm{OH}) \mathrm{D}$ and comorbidities (2) the relationship between vitamin D levels at admission and length of hospital stay in very old subjects admitted to an acute geriatric care unit.

\section{Materials and Methods}

Subjects and study design. This is a retrospective study conducted among 860 older adults consecutively admitted to the geriatric acute care unit of Santa Maria della Misericordia Hospital (University Hospital of Perugia) from January 2017 to January 2018. Only subjects aged 65 years and more, with available measurement of serum $25(\mathrm{OH}) \mathrm{D}$ at admission, who were able to give written informed consent, were included. Vitamin D and PTH form a tightly controlled feedback cycle, with PTH being a major stimulator of vitamin D synthesis while vitamin D exerts negative feedback on PTH secretion. Thus, subjects with hyperparathyroidism, fragility fractures within three months, or ongoing oral vitamin D supplementation were ruled out. A final cohort of 237 patients was included in the study. Data on demographics, anthropometrics, physical examination, clinical and biochemical characteristics were gathered from the hospitalization chart. The ethical committee of the University Hospital of Perugia approved the study protocol.

Analytical method. Blood samples were collected in the morning after the participants had been fasting for at least eight hours. Intact parathyroid hormone (PTHi), albumin, calcium, phosphorous, magnesium, creatinine, and C-reactive protein levels (CRP) were determined in serum by routine laboratory methods (Roche Diagnostics, $\mathrm{GmbH}$, Mannheim, Germany). Clearance creatinine has been calculated by the BIS-1 (Berlin Initiative Study) formula and expressed as $\mathrm{mL} / \mathrm{min} / 1.73 \mathrm{~m}^{2}$. Serum $25(\mathrm{OH}) \mathrm{D}$ concentrations were detected using the same routine test, for all subjects, at the hospital's laboratory by chemiluminescence immunoassays (CLIA), according to standard protocol. 
Group definition. Subjects were divided into four groups according to the serum concentration of $25(\mathrm{OH}) \mathrm{D}$ at admission. These are the thresholds used in the study [18]: optimal range (30-50 ng/mL), insufficiency $(20-30 \mathrm{ng} / \mathrm{mL})$, deficiency $(10-20 \mathrm{ng} / \mathrm{mL})$ and severe deficiency $(<10 \mathrm{ng} / \mathrm{mL})$. In addition, seasonality was determined considering fall (September, October, and November), winter (December, January, and February), spring (March, April, and May) and, summer (June, July, and August).

Cognitive, functional, and nutritional assessment. Cognitive performance was evaluated with the Mini Mental State Examination (MMSE) as a test of general cognition [19]. To avoid the underestimation of a self-rated level of functional capacity, an informant-based rating of functional status was carried out using the Basic Activities of Daily Living (BADL) [20] and the Instrumental Activities of Daily Living (IADL) scales [21]. BADL includes six activities: bathing, dressing, toileting, transferring, continence, and feeding. IADL includes eight activities: using the telephone, shopping, meal preparation, housekeeping, laundry, use of transportation, self-administration of drugs, and handling finances. Any dysfunction in the performances of these activities was recorded as dependence in the correspondent item. Because IADL items are often gender-specific, we used the version of the scale tested for male subjects that included only five items, with housekeeping, cooking, and doing laundry excluded. The BADL score ranges from 6 (total independence) to 0 (total dependence), and IADL from 8 (total independence) to 0 (total dependence) in women and from 5 (total independence) to 0 (total dependence) in men. The nutritional status was assessed by the administration of the Mini Nutritional Assessment (MNA) [22]. The MNA has been developed to assess malnutrition in elderly subjects and to select those who might benefit from early diagnosis and treatment. It is completed by a medical doctor and is comprised of 18 questions on (1) anthropometry, (2) dietary intake and habits, (3) general assessment, and (4) self-assessment. After completing the whole questionnaire, the total score (a maximum of 30 points) allows for grouping the nutritional status according to clearly defined boundaries: above 24 is defined as good status; $17-23.5$ means at risk of malnutrition; below 17 is defined as malnourished [22].

Comorbidity. Comorbidity was evaluated with the Cumulative Illness Rating Scale (CIRS) [23]. This rating scale consists of 14 items covering heart, hypertension, vascular and respiratory disorders, a combined eye-ear-nose-throat item, upper and lower gastrointestinal systems, hepatobiliary system, kidney, genitourinary diseases, musculoskeletal diseases, endocrine/metabolic disorders, neurological system, and behavioral-psychiatric disorders. Severity in each single item is rated according to the following algorithm: $1=$ no, $2=$ mild, $3=$ moderate, $4=$ severe, $5=$ life-threatening. After the completion of CIRS by a medical doctor, two summary measures can be constructed: the illness Severity Index (CIRS-SI), which reflects the overall severity of diseases and the average rating of the 14 CIRS items, and the Comorbidity Index (CIRS-CI), computed by counting the number of items with a score $\geq 3$ (moderate to severe pathology). As a result, the CIRS-CI can be considered the number of clinically relevant concomitant diseases.

Statistical analyses. The observed data were normally distributed (Shapiro-Wilk W-test) and are presented as means \pm standard deviation (SD). To assess differences among groups, unpaired $t$-test, ANOVA or Pearson's Chi-squared $\left(\chi^{2}\right)$ test were used, as appropriate. Also, the Manthel-Hanzel test for trends was tested among groups. Simple and partial (controlling for age and gender) correlations were used to test relations between serum $25(\mathrm{OH}) \mathrm{D}$ concentrations, comorbidity indices, CRP, and length of hospital stay (LOS). The independent effect of comorbidities burden on 25(OH)D concentrations (dependent variable) was tested by a linear regression controlling by multiple covariates, including age, gender, season, albumin, BADL, IADL, and renal function. In this model gender is indicated as $\mathrm{M}=1$ and $\mathrm{F}=0$, while season is winter $=1$, spring $=2$, summer $=3$, autumn $=4$. All $p$ values are two-tailed, and the level of significance was set at $p \leq 0.05$. Statistical analyses were performed using the SPSS 20 software package (SPSS, Inc., Chicago, IL, USA). 


\section{Results}

\subsection{Sample Characteristics}

Table 1 shows the baseline characteristics of the whole cohort and is stratified by gender. Participants were more likely women $(177 ; 74.68 \%)$, with a mean age of $86.5 \pm 6.2$ years and with a high prevalence of comorbidity and polypharmacy. Comorbidity indices were indicative of a high burden of disease interfering with normal activity and requiring intensive care at admission. Participants were taking a mean of 6.51 drugs per day, with a rate of polypharmacy defined as $>5$ drugs and affecting $66.7 \%$ of participants. Overall, $13 \%$ of the participants had cognitive impairment, defined as MMSE score corrected by age and education lower than 23 . From a functional perspective, 131 subjects (55.2\%) had BADL $\leq 3,140$ women $(79 \%)$ had IADL $\leq 4$, and seven men (11.6\%) had IADL $\leq 2$, indicative of severe disability. In the whole cohort, $68.6 \%$ of subjects had an MNA score $\leq 23.5$, indicative of a malnutrition risk status or state of being malnourished. The mean $25(\mathrm{OH}) \mathrm{D}$ serum concentration was indicative of deficiency $(10.58 \pm 7.68 \mathrm{ng} / \mathrm{mL})$, with $56 \%$ of patients affected by severe deficiency. They had mean levels of PTHi indicative of secondary hyperparathyroidism. No gender interaction was found between the serum concentration of vitamin D and PTHi. No difference was found in the length of hospital stay between genders. In the whole population an inverse correlation between $25(\mathrm{OH}) \mathrm{D}$ serum concentration and PTHi $(r=-0.280, p<0.0001)$, controlling for age and gender, was found. No correlation was found between $25(\mathrm{OH}) \mathrm{D}$ and calcium $(p=0.887)$, phosphorus $(p=0.110)$, and magnesium $(p=0.099)$.

Table 1. Baseline population sample characteristics $(n=237)$.

\begin{tabular}{|c|c|c|c|c|}
\hline & $\begin{array}{c}\text { Total Sample } \\
\quad N=237\end{array}$ & $\begin{array}{c}\text { Men } \\
N=60\end{array}$ & $\begin{array}{l}\text { Women } \\
N=177\end{array}$ & $p$ \\
\hline Age, $y$ & $86.5 \pm 6.2$ & $86.12 \pm 6.45$ & $87.18 \pm 6.22$ & 0.258 \\
\hline Drugs, $\mathrm{n}$ & $6.51 \pm 3.20$ & $7.43 \pm 3.08$ & $6.19 \pm 3.19$ & 0.013 \\
\hline CIRS-SI & $1.87 \pm 1.33$ & $2.15 \pm 1.43$ & $1.78 \pm 1.28$ & 0.062 \\
\hline CIRS-CI & $1.18 \pm 0.40$ & $1.27 \pm 0.41$ & $1.16 \pm 0.40$ & 0.069 \\
\hline MMSE adjusted & $22.8 \pm 4.7$ & $23.6 \pm 4.5$ & $22.8 \pm 4.4$ & 0.532 \\
\hline MMSE $\leq 23(n, \%)$ & $31(13.1)$ & $4(6.6)$ & $27(15.2)$ & 0.063 \\
\hline BADL & $2.76 \pm 2.16$ & $2.82 \pm 2.39$ & $2.73 \pm 2.09$ & 0.793 \\
\hline IADL & $2.14 \pm 2.70$ & $2.23 \pm 2.60$ & $2.10 \pm 2.66$ & 0.756 \\
\hline MNA & $21.08 \pm 3.71$ & $21.36 \pm 3.50$ & $21.04 \pm 3.76$ & 0.660 \\
\hline $25(\mathrm{OH}) \mathrm{D}(\mathrm{ng} / \mathrm{mL})$ & $10.58 \pm 7.68$ & $9.53 \pm 7.13$ & $10.94 \pm 7.83$ & 0.218 \\
\hline PTHi (pg/mL) & $112.9 \pm 112.9$ & $101.16 \pm 85.38$ & $116.00 \pm 121.31$ & 0.556 \\
\hline Albumin & $3.26 \pm 1.15$ & $3.22 \pm 1.01$ & $3.28 \pm 1.20$ & 0.733 \\
\hline Calcium, corrected (mg/dL) & $8.55 \pm 2.47$ & $8.68 \pm 2.08$ & $8.51 \pm 2.59$ & 0.651 \\
\hline Phosphorus (mg/dL) & $2.70 \pm 1.85$ & $2.95 \pm 1.91$ & $2.61 \pm 1.83$ & 0.218 \\
\hline Magnesium (mg/dL) & $1.20 \pm 1.02$ & $1.21 \pm 1.03$ & $1.19 \pm 1.02$ & 0.884 \\
\hline $\mathrm{CRP}(\mathrm{mg} / \mathrm{L})$ & $5.02 \pm 6.07$ & $6.15 \pm 7.10$ & $4.64 \pm 5.66$ & 0.120 \\
\hline Clearance creatinine (BIS1) & $41.3 \pm 19.5$ & $42.23 \pm 22.98$ & $39.74 \pm 18.00$ & 0.027 \\
\hline Length of hospital stay (days) & $12.33 \pm 9.22$ & $12.10 \pm 9.28$ & $10.01 \pm 9.08$ & 0.510 \\
\hline
\end{tabular}

Unless otherwise noted, data are presented as means \pm SD. CIRS-SI: Cumulative Illness Rating Scale-Severity index; CIRS-CI: Cumulative Illness Rating Scale-Comorbidity index; MMSE: Mini Mental State Examination (corrected by age and education); BADL: Basic Activities of daily living; IADL: Instrumental activities of daily living; MNA: Mini Nutritional Assessment; 25(OH)D: 25-hydroxyvitamin D; PTHi: Intact Parathyroid Hormone; CRP: C-reactive protein; Clearance creatinine calculated by BIS-1 (Berlin Initiative Study) formula and expressed as $\mathrm{ml} / \mathrm{min} / 1.73 \mathrm{~m}^{2}$.

\subsection{Sample Characteristics Stratified by Vitamin D Status}

Almost the entire sample (98.7\%) had 25(OH)D insufficiency, with one in two and one in three participants affected by a severe deficiency (56.6\%) and deficiency (29.9\%), respectively. Only three patients $(1.3 \%)$ were in the optimal range (Table 2$)$. In the severe deficiency groups, subjects were older, were more dependent in IADL, more likely malnourished, and had a high level of PTHi. Participants with severe deficiency of $25(\mathrm{OH}) \mathrm{D}$ had a significantly higher comorbidity index and comorbidity 
severity index as compared with other groups, with a statistically significant trend across groups $(p<0.0001)$. No difference was found in the length of hospital stay among vitamin D status groups. Table 3 shows the rate of vitamin D status in different seasons in the whole population sample. No significant difference was found in vitamin D status among seasons.

Table 2. Clinical characteristics of patients stratified by vitamin D status.

\begin{tabular}{|c|c|c|c|c|c|}
\hline & $\begin{array}{c}\text { Severe } \\
\text { Deficiency } \\
(<10 \mathrm{ng} / \mathrm{mL})\end{array}$ & $\begin{array}{c}\text { Deficiency } \\
(10-20 \mathrm{ng} / \mathrm{mL})\end{array}$ & $\begin{array}{l}\text { Insufficiency } \\
(20-30 \mathrm{ng} / \mathrm{mL})\end{array}$ & $\begin{array}{c}\text { Optimal } \\
\text { Range } \\
(30-50 \mathrm{ng} / \mathrm{mL})\end{array}$ & $p$ \\
\hline $\mathrm{N}(\%)$ & $134(56.6)$ & $71(29.9)$ & 29(13.2) & $3(1.3)$ & \\
\hline Age, y & $87.8 \pm 6.5$ & $85.6 \pm 6.4$ & $85.7 \pm 4.1$ & $85.3 \pm 2.0$ & 0.057 \\
\hline Gender M/F, $n$ & $34 / 100$ & $21 / 50$ & $4 / 25$ & $1 / 2$ & 0.420 \\
\hline Gender M/F, \% & $24.4 / 74.6$ & $29.5 / 70.5$ & $13.8 / 86.2$ & $87 / 12$ & 0.420 \\
\hline Drugs, n & $6.21 \pm 2.97$ & $7.25 \pm 3.33$ & $6.31 \pm 3.87$ & $4.50 \pm 0.70$ & 0.148 \\
\hline CIRS-SI & $1.27 \pm 0.43$ & $1.14 \pm 0.34$ & $0.97 \pm 0.32$ & $0.71 \pm 0.07$ & $<0.0001$ \\
\hline CIRS-CI & $2.21 \pm 1.42$ & $1.56 \pm 0.95$ & $1.28 \pm 1.25$ & $0.0 \pm 0.0$ & $<0.0001$ \\
\hline MMSE adjusted & $22.40 \pm 5.20$ & $23.57 \pm 4.05$ & $23.23 \pm 3.08$ & $25.75 \pm 2.21$ & 0.465 \\
\hline BADL & $2.40 \pm 2.10$ & $3.19 \pm 2.93$ & $3.26 \pm 2.14$ & $3.00 \pm 2.64$ & 0.056 \\
\hline IADL & $1.61 \pm 2.35$ & $2.90 \pm 2.93$ & $2.48 \pm 2.68$ & $3.33 \pm 3.51$ & 0.009 \\
\hline MNA & $20.36 \pm 3.65$ & $22.73 \pm 2.87$ & $19.95 \pm 4.54$ & $23.67 \pm 0.57$ & 0.001 \\
\hline PTHi (pg/mL) & $136.7 \pm 125.3$ & $95.5 \pm 101.4$ & $61.9 \pm 39.1$ & $34.0 \pm 8.1$ & 0.012 \\
\hline Albumin (g/dL) & $3.19 \pm 1.16$ & $3.35 \pm 1.16$ & $3.32 \pm 1.16$ & $3.5 \pm 0.36$ & 0.757 \\
\hline Calcium, corrected (mg/dL) & $8.45 \pm 2.44$ & $8.47 \pm 2.74$ & $9.13 \pm 1.99$ & $9.42 \pm 0.25$ & 0.525 \\
\hline Phosphorus (mg/dL) & $2.53 \pm 1.99$ & $2.76 \pm 1.64$ & $3.22 \pm 1.70$ & $3.73 \pm 0.92$ & 0.226 \\
\hline Magnesium (mg/dL) & $1.08 \pm 1.04$ & $1.30 \pm 0.99$ & $1.46 \pm 0.94$ & $1.36 \pm 1.18$ & 0.205 \\
\hline $\mathrm{CRP}(\mathrm{mg} / \mathrm{L})$ & $5.51 \pm 6.18$ & $4.30 \pm 5.98$ & $4.70 \pm 5.97$ & $2.20 \pm 2.40$ & 0.546 \\
\hline Clearance creatinine (BIS1) & $41.29 \pm 18.75$ & $42.65 \pm 21.82$ & $40.23 \pm 18.13$ & $27.50 \pm 5.21$ & 0.594 \\
\hline Length of hospital stay (days) & $11.83 \pm 8.14$ & $13.00 \pm 10.87$ & $13.06 \pm 9.81$ & $12.00 \pm 9.84$ & 0.816 \\
\hline
\end{tabular}

Table 3. The rate of overall vitamin D status in different seasons in the whole cohort. $X^{2}=10.055$, $p=0.346$.

\begin{tabular}{|c|c|c|c|c|}
\hline Season & $\begin{array}{l}\text { Severe Deficiency } \\
\quad(<10 \mathrm{ng} / \mathrm{mL})\end{array}$ & $\begin{array}{c}\text { Deficiency } \\
(10-20 \mathrm{ng} / \mathrm{mL})\end{array}$ & $\begin{array}{l}\text { Insufficiency } \\
(20-30 \mathrm{ng} / \mathrm{mL})\end{array}$ & $\begin{array}{c}\text { Optimal Range } \\
(30-50 \mathrm{ng} / \mathrm{mL})\end{array}$ \\
\hline Fall $n(\%)$ & $39(56.5)$ & $18(26.1)$ & $10(14.5)$ & $2(2.9)$ \\
\hline Winter $n(\%)$ & $16(44.4)$ & $13(36.1)$ & $6(16.7)$ & $1(2.8)$ \\
\hline Spring $n(\%)$ & $42(65.6)$ & $15(23.4)$ & $7(10.9)$ & $0(0)$ \\
\hline Summer $n(\%)$ & 37 (54.4) & $25(36.8)$ & $6(8.8)$ & $0(0)$ \\
\hline
\end{tabular}

\subsection{Vitamin D, Comorbidities Burden, CRP, and Length of Hospital Stay}

An inverse correlation was found between serum $25(\mathrm{OH}) \mathrm{D}$ concentrations and comorbidity indices CIRS-SI $(r$ : $-0.312 ; p<0.0001)$ and CIRS-CI $(r:-0.306 ; p<0.0001)$ in the entire sample (Figure 1A,B), even after adjustment for age and gender $(r:-0.281 ; p<0.0001$ and $r:-0.286 ; p<0.0001$, respectively). The independent effect of comorbidities burden on $25(\mathrm{OH}) \mathrm{D}$ levels was tested by a linear regression analysis controlling by multiple covariates. CIRS-SI (Table 4, Model 1) and CIRS-CI (Table 4, Model 2) remained inversely associated with $25(\mathrm{OH}) \mathrm{D}$ concentrations independent of age, gender, season, albumin, BADL, IADL, and renal function.

An inverse correlation was confirmed between serum $25(\mathrm{OH}) \mathrm{D}$ concentrations and CRP $(r=-0.142 ; p=0.041)$. As expected, CRP was also positively correlated with CIRS-SI $(r=0.209$, $p=0.003)$ and CIRS-CI $(r=0.158, p=0.023)$, but not with the length of hospital stay. Both CIRS-SI $(r=0.251, p<0.0001)$ and CIRS-CI $(r=0.137, p=0.016)$ were positively correlated with the length of hospital stay, while no significant correlation was found between $25(\mathrm{OH}) \mathrm{D}$ concentrations and length 
of hospital stay $(r=-0.006, p=0.932)$. In a final model with length of stay as the dependent variable and Vitamin D, CIRS-SI, and CRP as covariates, only CIRS-SI resulted significantly associated (data not shown).

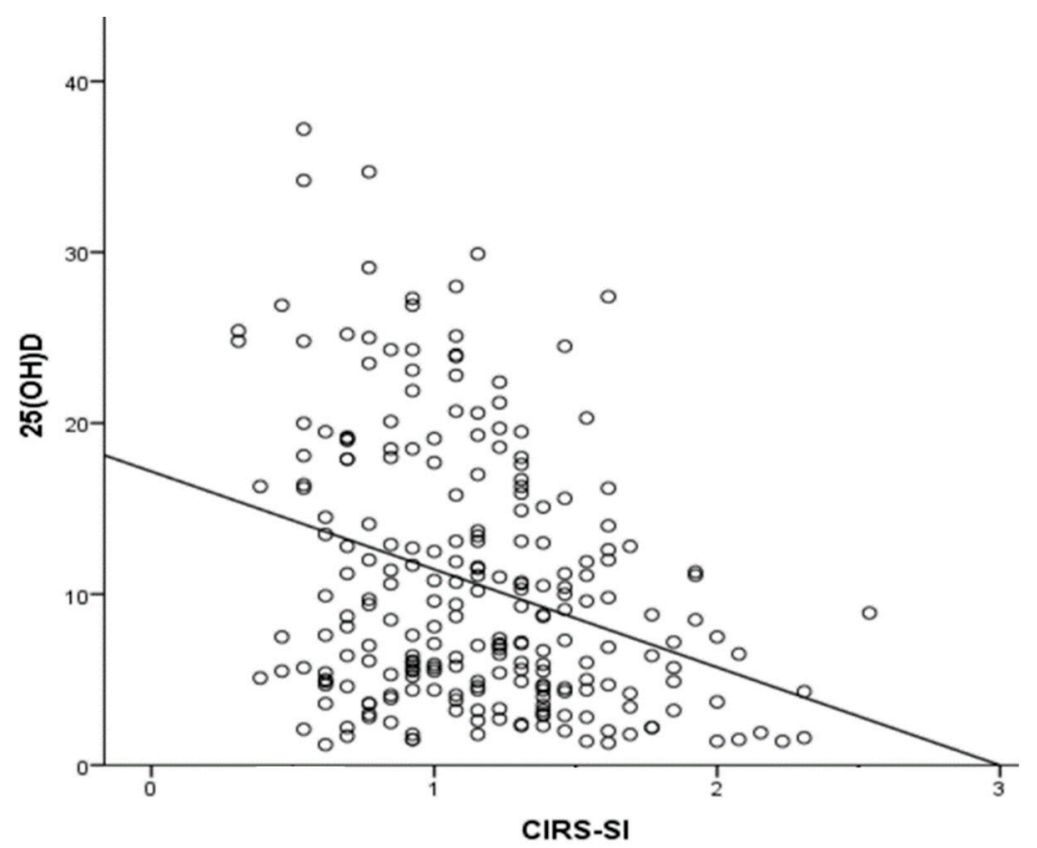

(A)

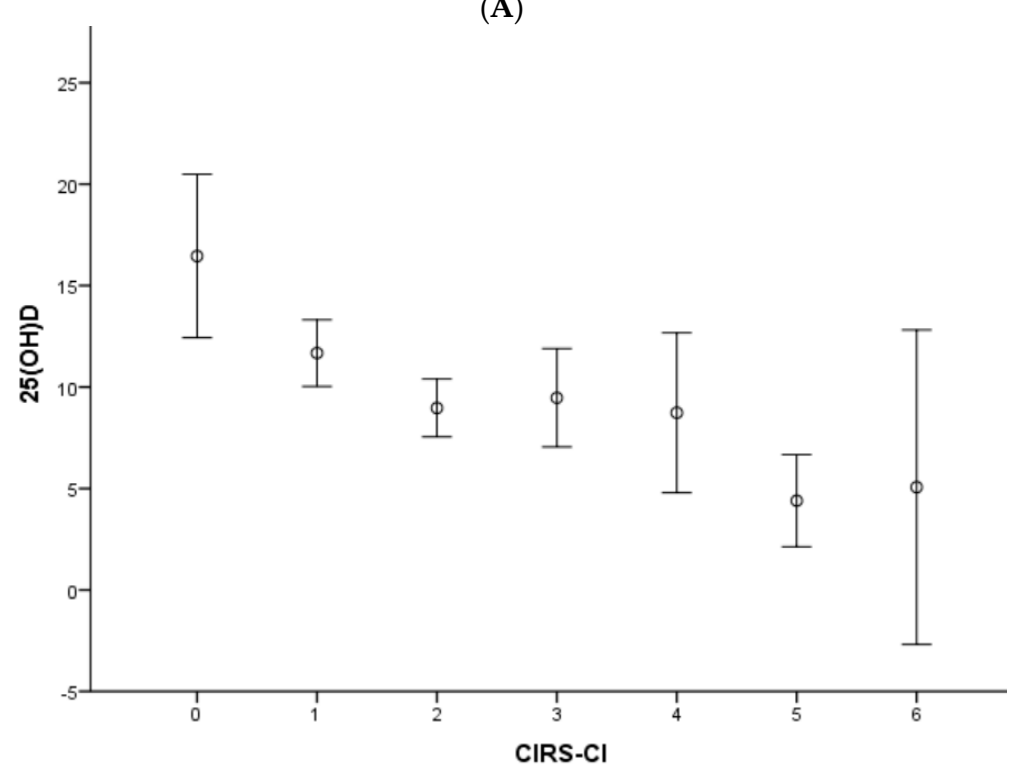

(B)

Figure 1. Simple correlation analysis between serum $25(\mathrm{OH}) \mathrm{D}$ concentrations and CIRS-SI (A) and CIRS-CI (B), in the whole cohort $(n=237)$. 25(OH)D: 25-hydroxyvitamin D expressed in ng/mL; CIRS-SI: Cumulative Illness Rating Scale-Severity index; CIRS-CI: Cumulative Illness Rating Scale-Comorbidity index. (A) Simple correlation between 25(OH)D concentration and CIRS-SI scores ( $r$ : $-0.312 ; p<0.0001)$; (B) simple correlation between $25(\mathrm{OH}) \mathrm{D}$ concentration and CIRS-CI $(r:-0.306 ; p<0.0001) . r=$ Pearson's correlation coefficient; $p=$ statistical significance of Pearson's correlation coefficient. 
Table 4. Linear regression analyses to assess whether comorbidities burden is associated with $25(\mathrm{OH}) \mathrm{D}$ concentrations controlling for multiple confounding factors $(n=237)$.

\begin{tabular}{ccc}
\hline Model 1 & B & $p$ \\
\hline Age & -0.097 & 0.292 \\
Gender & -1.083 & 0.363 \\
Season & -0.583 & 0.181 \\
Albumin & 0.446 & 0.317 \\
BADL & -0.047 & 0.900 \\
IADL & 0.034 & 0.926 \\
BIS1 & 0.083 & 0.793 \\
CIRS-SI & -6.322 & $<0.0001$ \\
\hline Model 2 & B & $p$ \\
Age & -0.103 & 0.266 \\
Gender & -1.386 & 0.242 \\
Season & -0.726 & 0.101 \\
Albumin & 0.335 & 0.452 \\
BADL & 0.031 & 0.934 \\
IADL & 0.178 & 0.573 \\
BIS1 & 0.000 & 0.995 \\
CIRS-CI & -1.854 & $<0.0001$ \\
\hline M 1 & &
\end{tabular}

Gender indicated as $\mathrm{M}=1$ and $\mathrm{F}=0$; Season indicated as winter $=1$, spring $=2$, summer $=3$, autumn $=4$; BADL: Activity of daily living; IADL: instrumental activity of daily living; BIS1 Clearance creatinine calculated by BIS-1 (Berlin Initiative Study) formula and expressed as $\mathrm{mL} / \mathrm{min} / 1.73 \mathrm{~m}^{2}$; CIRS-SI: Cumulative Illness Rating Scale-Severity index; CIRS-CI: Cumulative Illness Rating Scale-Comorbidity index.

\section{Discussion}

Our results show that (1) the majority of hospitalized older persons have deficient levels of vitamin $\mathrm{D}$, irrespective of season; (2) indices of comorbidity burden are negatively associated with 25(OH)D serum concentrations independent of multiple confounding factors; (3) 25(OH)D negatively correlates with serum CRP levels; and (4) the comorbidities burden is correlated with higher CRP levels and longer length of hospital stay.

Vitamin D deficiency is increasingly recognized as a common problem among older persons, including medical [24], surgical [25], and critically ill hospitalized patients [26]. Consistent with previous findings, 98.7\% of our oldest-old hospitalized population had hypovitaminosis D [24-26].

In this cohort, subjects with severe deficiency in $25(\mathrm{OH}) \mathrm{D}$ concentration have a higher comorbidity burden, in term of both severity and complexity (CIRS-SI and CIRS-CI), as compared with those in the optimal range group As expected, a person affected by multiple diseases and with poor health status may curtail outdoor activities, may undergo changes in diet and lifestyle with low dietary intake of vitamin $\mathrm{D}$, low sunlight exposure, or may require drugs affecting vitamin $\mathrm{D}$ absorption or metabolism. Thus, low vitamin D concentrations may act as a surrogate of poor health rather than a marker of impaired cellular functions. On the other hand, it is possible to hypothesize that the comorbidity per se can directly exert an influence on the serum concentrations of vitamin $\mathrm{D}$, as supported by the inverse association between $25(\mathrm{OH}) \mathrm{D}$ and comorbidity indices independent of multiple covariates including age, gender, season, albumin level (as an indicator of nutritional status), and functional status.

Vitamin D plays a critical role in the functioning of the immune system [27]. Interestingly, a direct and inverse correlation between $25(\mathrm{OH}) \mathrm{D}$ concentrations and CRP, a sensitive biomarker for inflammation, has been found in some studies [28]. We found a significant inverse correlation between $25(\mathrm{OH}) \mathrm{D}$ and serum levels of CRP. Interestingly, CRP levels reflect the severity of response to injury in an acute care setting [29] and may be a determinant of clinical outcome, including the length of hospital stay. Here we found a correlation between CRP levels and comorbidities burden, which in turn is associated with the length of stay. 
Many previous studies have proposed vitamin D as a biomarker of a longer length of stay in acute care units [30,31]. Hypovitaminosis D doubled the risk of being hospitalized for more than 14 days in a geriatric acute care unit [30] and, in another study, the combination of hypovitaminosis D, male gender, and delirium predicted a 4.8-fold higher risk of longer LOS among geriatric inpatients [31]. Another study showed that older patients with serum $25(\mathrm{OH}) \mathrm{D} \leq 50 \mathrm{nmol} / \mathrm{L}$ at the time of admission to the hospital had a LOS extended by approximately three days compared to those with $25(\mathrm{OH}) \mathrm{D}>$ $50 \mathrm{nmol} / \mathrm{L}$ [14]. Additionally, they reported the first evidence of a linear association between 25(OH)D concentrations and LOS, suggesting that any increase in $25(\mathrm{OH}) \mathrm{D}$ was associated with a decrease in LOS, irrespective of the initial vitamin D status [14]. We did not find a difference in the length of hospital stay among vitamin D status groups. A causal relationship between vitamin D levels and this specific outcome cannot be directly established considering that other variables could potentially influence the LOS: functional status score, illness severity, cognitive score, poor nutrition, comorbidity score, diagnosis or presenting illness, polypharmacy, age, and gender. A prospective multicenter study that included 250 intensive care unit (ICU) patients shows that vitamin D insufficiency is common in critically ill patients $(69 \%)$ and vitamin D-deficient patients had more severe diseases, according to the Acute Physiology and Chronic Health Disease Classification System II score, but this is not an independent risk factor for longer ICU stay or mortality [13]. Accordingly, we found that a higher comorbidities burden is associated with lower $25(\mathrm{OH}) \mathrm{D}$ serum concentrations independent of multiple covariates. Moreover, we found that both CIRS-SI and CIRS-CI indices significantly correlated with $\mathrm{CRP}$ as well as the length of hospital stay. These results strongly support the importance of the determination of $25(\mathrm{OH}) \mathrm{D}$ as a potential measure of the patient's comorbidity as well as vulnerability during hospitalization.

The current Italian guidelines state that measurement of serum 25(OH)D concentrations, whose cost is considerable, is not always justified from a health cost standpoint, especially in the elderly subject, as hypovitaminosis $\mathrm{D}$ is highly prevalent in this population. Neither routine nor screening assessments of serum $25(\mathrm{OH}) \mathrm{D}$ are recommended; they should be limited to doubtful cases or in the presence of comorbidities that increase the risk of severe hypercalcemia (e.g., granulomatosis) [17]. The National Osteoporosis Society (NOS) recommends the measurement of serum 25(OH)D to estimate vitamin D status only in the following clinical scenarios: bone diseases that may be improved with vitamin $\mathrm{D}$ treatment; bone diseases, prior to specific treatment where correcting vitamin D deficiency is appropriate; and musculoskeletal symptoms that could be attributed to vitamin D deficiency. The guidelines also state that routine vitamin $\mathrm{D}$ testing is unnecessary where vitamin $\mathrm{D}$ supplementation with an oral antiresorptive treatment is already planned.

It is challenging to clarify whether vitamin D deficiency is the cause or only the consequence of various chronic diseases. However, with this study, we provide evidence that vitamin D status may be used as a biomarker of comorbidities burden and indirectly as a determinant of clinical outcome, including LOS. Whether screening and supplementation of vitamin D deficiency can improve clinical outcomes and in particular LOS remains unclear. Variations in patient responses to acute and critical illness may depend on the degree of vitamin D insufficiency. Future studies are needed to determine how this marker can change over time and affect clinical outcomes.

Author Contributions: Conceptualization, V.B.; Methodology, V.B. and M.F.C. and M.B. and S.E.; Formal Analysis, V.B.; Investigation, V.B. and C.R.; Data Curation, V.B. and M.L. and L.G. and F.M.G; Writing - Original Draft Preparation, V.B. and M.L.; Writing-Review \& Editing, V.B. and C.R.; Supervision, P.M.; Project Administration, V.B. and C.R.

Funding: This research received no external funding.

Conflicts of Interest: The authors declare no conflict of interest. 


\section{References}

1. Holick, M.F.; Binkley, N.C.; Bischoff-Ferrari, H.A.; Gordon, C.M.; Hanley, D.A.; Heaney, R.P.; Murad, M.H.; Weaver, C.M. Evaluation, treatment, and prevention of vitamin D deficiency: An Endocrine Society clinical practice guideline. J. Clin. Endocrinol. Metab. 2011, 96, 1911-1930. [CrossRef] [PubMed]

2. Maggio, D.; Cherubini, A.; Lauretani, F.; Russo, R.C.; Bartali, B.; Pierandrei, M.; Ruggiero, C.; Macchiarulo, M.C.; Giorgino, R.; Minisola, S.; et al. 25(OH)D Serum levels decline with age earlier in women than in men and less efficiently prevent compensatory hyperparathyroidism in older adults. J. Gerontol. A Biol. Sci. Med. Sci. 2005, 60, 1414-1419. [CrossRef] [PubMed]

3. Hutchinson, M.S.; Grimnes, G.; Joakimsen, R.M.; Figenschau, Y.; Jorde, R. Low serum 25-hydroxyvitamin D levels are associated with increased all-cause mortality risk in a general population: The Tromso study. Eur. J. Endocrinol. 2010, 162, 935-942. [CrossRef] [PubMed]

4. Holick, M.F. Vitamin D deficiency. N. Engl. J. Med. 2007, 357, 266-281. [CrossRef] [PubMed]

5. Melamed, M.L.; Michos, E.D.; Post, W.; Astor, B. 25-hydroxyvitaminD levels and the risk of mortality in the general population. Arch. Intern. Med. 2008, 168, 1629-1637. [CrossRef] [PubMed]

6. Autier, P.; Gandini, S. Vitamin D supplementation and total mortality: A meta-analysis of randomized controlled trials. Arch. Intern. Med. 2007, 167, 1730-1737. [CrossRef]

7. Beauchet, O.; Helard, L.; Montero-Odasso, M.; De Decker, L.; Berrut, G.; Annweiler, C. Hypovitaminosis D in geriatric inpatients: A marker of severity of chronic diseases. Aging Clin. Exp. Res. 2012, 24, 188-192.

8. Sutra del Galy, A.; Bertrand, M.; Bigot, T.; Abraham, P.; Thomlinson, R.; Paccalin, M.; Beauchet, O.; Annweiler, C. Vitamin D insufficiency and acute care in geriatric inpatients. J. Am. Geriatr. Soc. 2009, 57, 1721-1723. [CrossRef] [PubMed]

9. Annweiler, C.; Pochic, S.; Fantino, B.; Legrand, E.; Bataille, R.; Montero-Odasso, M.; Beauchet, O. Serum vitamin $\mathrm{D}$ concentration and short-term mortality among geriatric inpatients in acute care settings. Adv. Ther. 2010, 27, 245-249. [CrossRef]

10. Zhang, Y.P.; Wan, Y.D.; Sun, T.W.; Kan, Q.C.; Wang, L.X. Association between vitamin D deficiency and mortality in critically ill adult patients: A meta-analysis of cohort studies. Crit. Care 2014, 18, 684. [CrossRef]

11. De Haan, K.; Groeneveld, A.B.; de Geus, H.R.; Egal, M.; Struijs, A. Vitamin D deficiency as a risk factor for infection, sepsis and mortality in the critically ill: Systematic review and meta-analysis. Crit. Care 2014, 18, 660. [CrossRef] [PubMed]

12. Blay, B.; Thomas, S.; Coffey, R.; Jones, L.; Murphy, C.V. Low Vitamin D Level on Admission for Burn Injury Is Associated with Increased Length of Stay. J. Burn Care Res. 2017, 38, e8-e13. [CrossRef] [PubMed]

13. Anwar, E.; Hamdy, G.; Taher, E.; Fawzy, E.; Abdulattif, S.; Attia, M.H. Burden and Outcome of Vitamin D Deficiency Among Critically Ill Patients: A Prospective Study. Nutr. Clin. Pract. 2017, 3, 378-384. [CrossRef] [PubMed]

14. Hélard, L.; Mateus-Hamdan, L.; Beauchet, O.; Annweiler, C. Hypovitaminosis D in Geriatric Acute Care Unit: A Biomarker of Longer Length of Stay. Hindawi Publ. Corp. Dis. Mark. 2013, 35, 525-529. [CrossRef]

15. Autier, P.; Boniol, M.; Pizot, C.; Mullie, P. Vitamin D status and ill health: A systematic review. Lancet Diabetes Endocrinol. 2014, 2, 76-89. [CrossRef]

16. Amrein, K.; Schnedl, C.; Holl, A.; Riedl, R.; Christopher, K.B.; Pachler, C.; Urbanic Purkart, T.; Waltensdorfer, A.; Münch, A.; Warnkross, H.; et al. Effect of high-dose vitamin D3 on hospital length of stay in critically ill patients with vitamin D deficiency: The VITdAL-ICU randomized clinical trial. JAMA 2014, 312, 1520-1530. [CrossRef] [PubMed]

17. Schottker, B.; Saum, K.U.; Perna, L.; Ordóñez-Mena, J.M.; Holleczek, B.; Brenner, H. Is vitamin D deficiency a cause of increased morbidityand mortality at older age or simply an indicator of poor health. Eur. J. Epidemiol. 2014, 29, 199-210. [CrossRef] [PubMed]

18. Rossini, M.; Adami, S.; Bertoldo, F.; Diacinti, D.; Gatti, D.; Giannini, S.; Giusti, A.; Malavolta, N.; Minisola, S.; Osella, G.; et al. Guidelines for the diagnosis, preventionand management of osteoporosis. Reumatismo 2016, 68, 1-39. [CrossRef]

19. Folstein, M.; Folstein, S.; McHugh, P.R. Mini Mental State: A practical method for grading the cognitive state of patients for the clinician. J. Psychiatr. Res. 1975, 12, 189-198. [CrossRef]

20. Katz, S.; Ford, A.B.; Moskowitz, R.W.; Jackson, B.A.; Jaffe, M.W. Studies of illness in the aged. The index of ADL: A standardized measure of biological and psychosocial function. JAMA 1963, 185, 914-919. [CrossRef] 
21. Graf, C. The Lawton instrumental activities of daily living (IADL) scale. Medsurg Nurs. 2008, 17, $343-344$. [PubMed]

22. Guigoz, Y.; Vellas, B. Mini Nutritional Asssessment, a practical assessment tool for grading the nutritional state of elderly patients. Facts Res. Gerontol. 1994, 2, 15-59.

23. Miller, M.D.; Paradis, C.F.; Houck, P.R.; Mazumdar, S.; Stack, J.A.; Rifai, A.H.; Mulsant, B.; Reynolds, C.F. Rating chronic medical illness burden in geropsychiatric practice and research: Application of the Cumulative Illness Rating Scale. Psychiatry Res. 1992, 41, 237-248. [CrossRef]

24. Kiebzak, G.M.; Moore, N.L.; Margolis, S.; Hollis, B.; Kevorkian, C.G. Vitamin D status of patients admitted to a hospital rehabilitation unit: Relationship to function and progress. Am. J. Phys. Med. Rehabil. 2007, 86, 435-445. [CrossRef] [PubMed]

25. Quraishi, S.A.; Bittner, E.A.; Blum, L.; Hutter, M.M.; Camargo, C.A. Association between preoperative 25-hydroxyvitamin $\mathrm{D}$ level and hospital-acquired infections following roux-en-Y gastric bypass surgery. JAMA Surg. 2014, 149, 112-118. [CrossRef]

26. Lee, P.; Eisman, J.A.; Center, J.R. Vitamin D deficiency in critically ill patients. N. Engl. J. Med. 2009, 360, 1912-1914. [CrossRef] [PubMed]

27. Schwalfenberg, G.K. A review of the critical role of vitamin D in the functioning of the immune system and the clinical implications of vitamin D deficiency. Mol. Nutr. Food Res. 2011, 55, 96-108. [CrossRef] [PubMed]

28. Maggio, M.; de Vita, F.; Lauretani, F.; Bandinelli, S.; Semba, R.D.; Bartali, B.; Cherubini, A.; Cappola, A.R.; Ceda, G.P.; Ferrucci, L. Relationship between Carotenoids, Retinol, and Estradiol Levels in Older Women. Nutrients 2015, 7, 6506-6519. [CrossRef]

29. Jafarnejad, S.; Boccardi, V.; Hosseni, B.; Taghizadeh, M.; Hamedifard, Z. A Meta-analysis of Randomized Control Trials: The Impact of Vitamin C Supplementation on Serum CRP and serum hs-CRP Concentrations. Curr. Pharm. Des. 2018, 24, 3520-3528. [CrossRef]

30. Beauchet, O.; Launay, C.P.; Maunoury, F.; de Decker, L.; Fantino, B.; Annweiler, C. Association between vitamin D deficiency and long hospital stay in geriatric acute care unit: Results from a pilot cohort study. Aging Clin. Exp. Res. 2013, 25, 107-109. [CrossRef]

31. Beauchet, O.; Launay, C.; de Decker, L.; Fantino, B.; Kabeshova, A.; Annweiler, C. Who is at risk of long hospital stay among patients admitted to geriatric acute care unit? Results from a prospective cohort study. J. Nutr. Health Aging 2013, 17, 695-699. [CrossRef] [PubMed] 